\title{
A behavioral change-based approach to energy efficiency in a manufacturing plant
}

\author{
Krushna Mahapatra $(\mathbb{D} \cdot$ Rickard Alm • \\ Ramona Hallgren • Lena Bischoff • Nil Tuglu • \\ Le Kuai • Ye Yang • Ibrahim Umoru
}

Received: 2 March 2017 / Accepted: 16 October 2017 /Published online: 9 November 2017

(C) The Author(s) 2017. This article is an open access publication

\begin{abstract}
In the realm of industrial energy efficiency studies, very little research has been done to understand the barriers and opportunities to influence behavior of production workers and the corresponding energysaving potentials. This paper analyzes a case study of Volvo Construction Equipment AB in Braås, Sweden (VCE Braås), that has reduced its relative idle electricity use by more than 10 percentage points during 20132016 by implementing a strategy of changing everyday
\end{abstract}

K. Mahapatra $(\bowtie) \cdot$ R. Hallgren $\cdot$ L. Bischoff $\cdot$ N. Tuglu •

L. Kuai · Y. Yang · I. Umoru

Linnaeus University, SE-351 95 Växjö, Sweden

e-mail: krushna.mahapatra@lnu.se

R. Hallgren

e-mail: rh222dt@student.lnu.se

L. Bischoff

e-mail: ab223ij@student.lnu.se

N. Tuglu

e-mail: tuglu.nil@gmail.com

L. Kuai

e-mail: 1k222nr@student.lnu.se

Y. Yang

e-mail: yy222av@student.lnu.se

I. Umoru

e-mail: iu222aj@student.lnu.se

R. Alm

Volvo Construction Equipment, SE-351 95 Braås, Sweden e-mail: rickard.alm@volvo.com behavior of production workers. The results based on interviews with actors involved in the energy efficiency project showed that a concrete goal, the employment of a fulltime operational leader who earlier worked as a production worker at VCE Braås, and the involvement of both the leadership and employees in project management were key to the success of the project.

Keywords Industry · Energy efficiency · Energy management $\cdot$ Behavior

\section{Introduction}

The European Union has a target to reduce energy use by at least by $27 \%$, reduce greenhouse gas emission by $40 \%$, and increase the share of renewable energy use by 27\% (European Commission 2017a). The industrial sector, which is responsible for $26 \%$ in the final energy consumption of the EU-28 countries (European Commission 2017b), offers significant opportunities to achieve these targets. Many industrial organizations have improved their energy performance through the implementation of energy audits and energy management system ISO50001. Energy efficiency of the European industry sector has improved by $1.4 \%$ per year since 2000 (ODYSSEE-MURE 2015), but there remains a large potential for energy saving, even in the most mature industries (Chirez 2016).

In Sweden, final energy use in the industrial sector has remained almost constant since the 1970s in spite of significant increase in production, but the share of 
electricity in the final energy use of that sector has increased from $21 \%$ in 1970 to $35 \%$ in 2013 (SEA 2016). To promote energy efficiency, the Swedish Energy Agency implemented the "program for energy efficiency of energy intensive industries (PFE)" during the period 2004-2014. The program resulted in 10\% reduction in energy use of the participating companies (equivalent to total $3 \mathrm{TWh}$ electricity) compared to the PFE situation (Björkman et al. 2016). ${ }^{1}$ However, only 103 companies out of more than 1000 potential enterprises participated and some large corporations in the metal, refinery, and chemical sectors were not eligible to join the program (Björkman et al. 2016). This suggests that there is still significant potential to improve energy efficiency of the Swedish industrial sector. However, several economical, organizational, and behaviorrelated barriers prevent the potential to be realized (Thollander and Palm 2013). Since the year 2014, the law on energy audits in large companies specifies that large companies ${ }^{2}$ have to undergo mandatory energy efficiency audits every 4 years (SEA 2016).

Energy reduction strategies have gained popularity with other areas such as logistics having exhausted their potential for optimization (Bunse et al. 2011). A change in energy strategies is useful not only to reduce costs but also to promote corporate social responsibility (Flammer 2013). However, industrial energy efficiency studies have mostly focused on technological solutions and hindrances to investment-oriented measures without any substantive attention in understanding the nontechnological aspects. Backlund et al. (2012a) have introduced the "extended energy efficiency gap" concept to illustrate that energy efficiency in the industrial sector could be better achieved by incorporating energy management of the innovative technologies rather than by concentrating only on the barriers to technological investment as has been the case with the traditional "energy efficiency gap" discourse. Backlund et al. (2012b) reported that the Swedish manufacturing firms perceived that the energy efficiency potential of technological investments or their management would be similar.

An integral part of energy management in a manufacturing plant is to increase knowledge and

\footnotetext{
${ }^{1}$ Apart from implementation of the ISO 50001 Standard, the participating companies got several other side benefits due to their participation in PFE (see Björkman et al. 2016 for more).

${ }^{2}$ Employing at least 250 people and has an annual turnover exceeding $€ 50$ million or an annual balance sheet exceeding $€ 43$ million per year.
}

awareness of energy use and to continuously address the deficiencies (Abdelaziz et al. 2011; Björkman et al. 2016). The intervention may not necessarily involve heavy investments. Low-cost measures such as staff training and a change in day-to-day practices have been shown to have large overall effects (Bernstein et al. 2007). However, in the industrial energy efficiency literature, there is a lack of research on how to bring about such a change in habitual behavior. In this paper, an attempt has been to address this gap through a case study analysis.

To change habitual behavior is difficult, especially in the case of "preventive innovations" such as energy efficiency whose benefits or consequences may be unclear and accrue in distance future (Rogers 2003). Nevertheless, Volvo Construction Equipment $\mathrm{AB}$ at Braås (VCE Braås) in Sweden has implemented a behavioralchange strategy to reduce its relative idle electricity use (see Eq. 1 below) by more than 10 percentage point during 2013-2016. The strategy targeted changing everyday practices of the production workers such as turning off of machines or lights when not in operation. This paper analyzes the factors contributing to the energy efficiency achievements of VCE Braås. The empirical investigation did not cover all the organizational units of the plant, but was limited to the fabrication division where the behavioral interventional strategy was introduced.

\section{Behavioral energy efficiency approach of Volvo CE}

Volvo Construction Equipment (Volvo CE) is a part of the Volvo Group. It has 15 production sites across the globe, which manufacture machinery equipment used for quarries and aggregates, oil- and gas-related industries, heavy infrastructure, utilities, road construction, building, demolition, recycling industry, industrial material handling, and forestry industry. One of the core values of Volvo $\mathrm{CE}$ is to care for environment, e.g., through a commitment to $\mathrm{CO}_{2}$ neutral facilities and reduction in natural resource use, and the company is part of Volvo Group's WWF (Worldwide Fund for Nature) Climate Savers partnership (Volvo Construction Equipment 2011). In 2013, the Volvo CE Global Director of Manufacturing Engineering and Environmental Care introduced a plan to improve energy efficiency in all production sites of the company. The focus has been to reduce electricity use as it 
constituted about $50 \%$ of the total final energy use of Volvo CE, and in some production sites, the share was up to $75 \%$.

The energy efficiency plan is conceived to be realized by the following four steps:

1. Reduce idle electricity use during the off-production weekends (Saturday-Sunday).

2. Reduce idle electricity use during the off-production hours during weekdays (night time).

3. Reduce number and/or duration of production shifts, but keeping the production level constant.

4. Reduce energy use during production hours.

Volvo CE has implemented the plan by focusing on steps 1 and 2 during 2013-2015 and setting an energy efficiency target. The target was that the relative idle electricity use (Eq. 1) at each production site should not be more than $15 \%$ of the electricity used during production hours. Each production site was free to decide on its own how to reach the target. The measurement period for idle electricity use during off-production hours was from $7 \mathrm{p} . \mathrm{m}$. Saturday to $5 \mathrm{a} . \mathrm{m}$. Sunday $(10 \mathrm{~h})$ and that of the production electricity use was from 7 a.m. Monday to 5 p.m. Monday $(10 \mathrm{~h})$.

Relative idle electicity use (\%)

$=\frac{\text { Idle electricity use }(k W h \text { during } 10 \text { idle hours })}{\text { Production electricity use }(k W h \text { during } 10 \text { idle hours })} * 100$
VCE Braås approach

The production plant VCE Braås is the world's first $\mathrm{CO}_{2}$ neutral manufacturing plant and it produces haulers in up to three shifts. Approximately 850 employees are engaged in both production and non-production activities. The project of idle electricity reduction was started in 2013 by the leadership of the Environmental Care and Security Manager, who worked part-time in the project. The Environmental and Safety Technician, who previously worked in the fabrication division at VCE Braås for ca. 15 years, was employed as a fulltime operational leader of the project. The project leader and the operational leader jointly planned for a systematic implementation of the behavioral energy efficiency approach in the fabrication division. An overview of the approach is presented below. The top-down hierarchical position of the actors involved in the project and their responsibilities are outlined in Table 1 in the Method section.

- Environmental manager (part time) leads the project

- Employment of a fulltime operational leader

- Measurement of energy use of all production equipment over a week

- Project purpose is explained to the production leaders and group leaders by visualizing energy use and the potential for reductions

- Production leaders set own goals and draw action plans for their units

- Night walks, reinforced end of shift routines, and energy treasure hunts

Table 1 Overview of the interviewees involved in the energy efficiency project at VCE Braås

\begin{tabular}{|c|c|c|}
\hline $\begin{array}{l}\text { Position in the top to bottom } \\
\text { hierarchical level of the project }\end{array}$ & Responsibility & Type of interview \\
\hline $\begin{array}{l}\text { Global Director for Manufacturing } \\
\text { Engineering and Environmental } \\
\text { Care of Volvo CE }\end{array}$ & $\begin{array}{l}\text { Overall responsibility for the energy efficiency project } \\
\text { at Volvo CE (parent company of VCE Braås) }\end{array}$ & Personal \\
\hline Environmental technician & Full-time operational leader of the project at VCE Braås & Personal \\
\hline $\begin{array}{l}\text { Production leaders of the } \\
\text { fabrication unit }\end{array}$ & $\begin{array}{l}\text { In charge of the group leaders and serve as an interface } \\
\text { between the floor workers and the management. } \\
\text { They spend } 40 \% \text { of their working time on the shop } \\
\text { floor and the rest in meetings or in their office. }\end{array}$ & One focus group with all 3 production leaders \\
\hline $\begin{array}{l}\text { Group leaders of the fabrication } \\
\text { unit }\end{array}$ & $\begin{array}{l}\text { Each group leader is responsible for approximately } 10 \\
\text { floor workers. Their assignment is to monitor floor } \\
\text { workers and distribute them across machines. }\end{array}$ & $\begin{array}{l}\text { Two focus groups with } 3 \text { respective } 4 \text { group } \\
\text { leaders out of } 9 \text { group leaders }\end{array}$ \\
\hline Floor workers & Operate the machines in the fabrication units & $\begin{array}{l}8 \text { floor workers selected randomly, but from } \\
\text { different age groups and gender to } \\
\text { represent the } 50-60 \text { floor workers }\end{array}$ \\
\hline
\end{tabular}


- Operational leader weekly meeting with group leaders

- Energy use statistic reported to Volvo CE management

At the onset of the project, four Fluke 1730 energy loggers are installed to measure electricity use of all equipment used in production over a whole week. The measured data forms the basis for the operational leader to interact with the production leaders and group leaders and explain them the context of the project. The process starts by approaching one production group (consists of a production leader, group leaders, and floor workers) that would be most interested in the project. The operational leader could identify such a group as he has good interpersonal network with other employees and is aware of their possible reaction to the project. The measured electricity use of individual equipment, the measured total idle electricity use, and the reduction goal of the plant are graphically presented to the production group. The argument for reducing idle electricity use revolves mainly around environmental sustainability such as reducing energy waste, mitigation of climate change, and the environmental goals of the company. However, the side benefits such as reduced costs and increased profitability for the company is mentioned, but without presenting any numbers or diagrams.

The production group develops and implements its own action plan of turning off machines and lights when not in use. Since the production workers have firsthand experience of different machines, they decide on which machines to be turned off and at what time (e.g., laser in a robot was switched off, but not the whole robot). The process then successively continues with inclusion of other production groups. A joint team of the project leader, operational leader, and some production workers conduct night walks and energy treasure hunts to check which machines and lights are running at off-production hours. Some production groups have reinforced end-ofshift routines to see that machines and lights are turned off.

The operational leader makes a weekly presentation of the measured energy use to the group leaders, while production leaders get an update every month. There is a Swedish coordinator to collect progress reports from all Swedish production sites, who forwards the reports to the Global Director of the project at Volvo CE. The Director conducts weekly meetings with the coordinator to track the progress. On a monthly basis, they consolidate the results into an A3 reporting template and send it out to all site managers, the top management, and environmental care managers. If any production plant does not reach the set goal of energy reduction, the Global Director discusses with the site general manager and the site representative of the energy efficiency project (e.g., project leader at VCE Braås) to understand the hindrances and how to move forward to achieve the goal.

\section{Theory}

A schematic diagram of the theoretical framework of factors affecting the performance of a behavior-based energy efficiency project is presented in Fig. 1. It shows that energy saving is the result of employees' actions and action is triggered by their motivation. The motivation to act is influenced by several factors such as goals, personal and social norms, company culture, leadership, communication, and cooperation among the employees.

Foss and Lindenberg (2013) argue that management of motivation should be given priority in the management of organizational members. One way to nurture motivation is to set specific goals (e.g., energy efficiency target) as has been put forth by the "goal-setting theory" (Locke and Latham 1990, 2002). The need for setting a goal can arise out of the company context such as environmental values, corporate social responsibility, and improved profitability or because of global context such as government rules and regulations. Goal setting encourages participants to put in substantial effort and therefore, is an important tool for managers to improve employee performance (Locke and Latham 1990, 2002; Evans 1970). When a goal is set, it influences the functioning of the firm through their influence on the firm's internal governance and motivation of the employees, including the top management (Foss and Lindenberg 2013). However, successful goal achievement requires that employees are committed to the goal (Rohdin and Thollander 2006). If the objectives of the goal or the expected outcomes were clearly explained to the participants, motivation increased (Locke and Latham 2002).

An action presupposes that people are aware of the problem their behavior causes or the benefit a change in behavior can create (Steg et al. 2013). This means the floor workers should be aware of the implication of the 


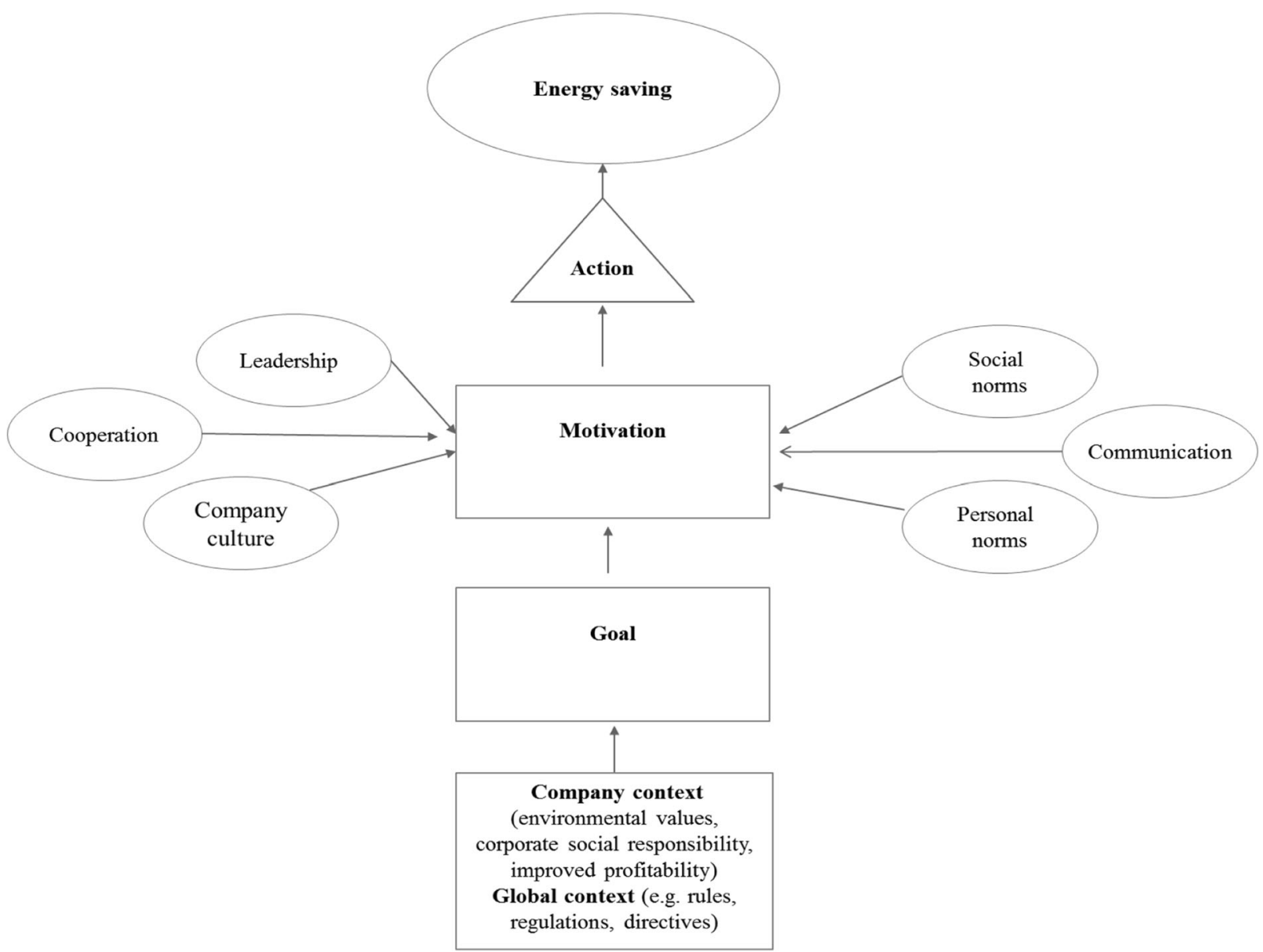

Fig. 1 A theoretical framework of factors affecting the performance of a behavior-based energy efficiency project

production activities on energy use and of the benefits of engaging in energy efficiency. Owen and Beevor (2009) suggested that awareness creation can be done through education or making the problem visible and tangible to the people. Nevertheless, successful goal achievement requires proper communication, i.e., regular information exchange between the change agent (e.g., company management) and the receiver (e.g., the floor workers) rather than dumping information (Rogers 2003). Communication helps convincing the people (i.e., floor workers) about the importance of committing to the set goal and to managing feedback. People are more likely to act on information if it is specific and communicated in a personal manner by a person related to the receiver (Thollander and Ottosson 2008, Thollander and Ottosson 2010).

An individual's personal norms, i.e., feelings of moral obligation to engage in particular environmental actions, guide pro-environmental intention or behavior
(Schwartz 1973; Harland et al. 1999; Stern et al. 1999; van der Werf and Steg 2016). Studies have shown that people who feel a moral obligation to protect the environment are also more likely to intend on reducing personal-car use (Nordlund and Garvill 2003), to intend on using public transportation (Bamberg and Möser 2007), or to purchase organic food products (Thøgersen and Ölander 2006).

Environmental behavior is also guided by social norms, i.e., the explicit and implicit "rules," guidelines, or behavioral expectations within a group or society that shape what is deemed normal or desirable (Ajzen 1991; Cialdini and Trost 1998; Frederiks et al. 2015). In other words, norms are prescriptions that tell members what they should and should not do under certain circumstances. For example, if many of your colleagues come to the workplace by bicycle, then you may also consider to bike to work. Similarly, in Sweden, it is a social norm for the employees to take part in "fika" or coffee break. 
To achieve organizational goals, it is fundamental for the members to cooperate despite their self-interests (Håkonsson et al. 2016). Cooperation is important to achieve a common goal, which is beyond the reach of an individual, while there may not be any direct personal gains (Håkonsson et al. 2016). Nevertheless, cooperation gives the employees an opportunity to be visible and acknowledged, which motivates them for joint effort (Johansson 2015). Hence, employee involvement in a project and the ability to cooperate with others may affect behavioral-based energy reduction (Johansson 2015).

Organizational culture may affect the performance of an organization (Shakil 2012; Kandula 2006). It represents the shared values, beliefs, and principles of the members (Schein 1990), and contributes to the unique social and psychological environment of an organization (Wikipedia 2017). Thus, when environmental values are anchored to company culture, employees are likely to engage in energy efficiency behavior (Sorrell et al. 2000) and take collective responsibility towards lowering energy consumption (Nisiforou et al. 2012).

The leadership of an organization may affect the success of attaining a goal (Nixon et al. 2012). When leaders or the managers serve as role models and are actively engaged in promoting energy saving, it positively affects success of an energy efficiency project (Johansson 2015; Nisiforou et al. 2012). The leadership can show their commitment to energy efficiency through a project setup in which a full-time project leader is appointed to fully dedicate his/her time and knowledge to the project (Johansson 2015). The appointment of such a leader contributes to make the decision chain as short and efficient as possible, which is important for success of a project (Thollander and Ottosson 2010). However, the influence of the project leader depends very much on the leader's personal characteristics, e.g., ability to motivate others through interpersonal networking (Thollander and Ottosson 2008).

\section{Method}

In this paper, a positivist approach, in which a theoretical construct is tested through collection of data (Bryman and Bell 2011), is used to analyze the factors affecting the energy efficiency achievement of VCE Braås. The investigation was limited only to the fabrication division, which was the starting point of testing the behavioral intervention approach. Semi-structured interviews, especially focus groups, were conducted as they are appropriate to explore and gather information related to experiences, attitudes, perspectives, and opinions (Bryman and Bell 2011). The interviews were conducted during February to April 2016 with people from different hierarchical level of the energy efficiency project as summarized in Table 1. Interviews were recorded using an electronic device, except for those with floor workers due to the loud production noise at the working space. For them, noting was made on paper.

A group of Master level students from Linnaeus University conducted the interviews. The only native Swedish-speaking student in the group conducted the interview with help from another semi-Swedishspeaking student. One interview was in English. After the interviews, the responses were summarized as written text. They were later updated after listening to the recordings (except for floor workers), which also helped scan typical quotes from the production leaders and group leaders. The native Swedish speaker narrated the interview results to be transcribed to English by the semi-Swedish speaker.

The aim of the semi-structured interview was to get a deeper insight into interviewees' reflection regarding the energy efficiency project. Therefore, "how" and "why" questions were paid attention to. The questions were about to understand the usefulness of the goals and feedbacks, how management creates awareness on the energy topic, leadership characteristics, cooperation, project setup, and so on. A sample list of questions posed to the production leaders and group leaders is presented in the box below. The floor workers were approached while working on the shop floor, and therefore, only few of these questions could be asked.

What does a typical day at work look like for you?

What do you think of this program to reduce energy? Explain.

How does the program affect you and your routines at work?

How do you motivate your group members to achieve the goal? Do they cooperate or hesitate or ignore?

What suggestions did you make to reduce energy at your station? How much were you able to decide? What was the reaction of workers?

The numbers or reports Frank (the operational leader) gives you every Tuesday, does it influence you somehow? How?

Do you think rewards will motivate you and your group to do better in the future if you do great work? What kind of rewards would help you get more motivated? (holiday? money? candy? or ...)

In what way do you think you are responsible for achieving the goal?

What do you do at home in order to reduce energy? 


\section{Results}

Energy efficiency achievement

The energy efficiency achievements of VCE Braås during 2013 to 2016 are presented in Fig. 2 and Fig. 3. Figure 2 shows the actual energy use during a typical week, which forms the basis for calculation of relative idle electricity consumption using Eq. 1. However, the outcome from this equation is sensitive to electricity use during the 10 productive hours ( 7 a.m. Monday to 5 p.m.) on Monday. If during that period machines were used to a greater capacity, then the electricity use was higher and thereby, the relative idle electricity use was lower. Figure 2 shows the measured electricity consumption during specific weeks in 2013, 2014, 2015, and 2016 with similar levels of production. It shows that idle electricity use has decreased not only during the 10 off-production hours in the weekend but also at night times on Monday to Thursday.

Figure 3 shows the actual idle electricity use in kilowatt hour (primary y-axis) during the 10 off-production hours ( 7 p.m. Saturday to 5 a.m. Sunday) and the relative idle electricity use (secondary y-axis) for each week. The chart contains data for every week, but due to space and legibility limitation, only the name of the month is visible in the X-axis. It can be seen that there is wide fluctuation in the actual kilowatt hour idle electricity use over the weeks, even though most of those weeks had no production during the measured $10 \mathrm{~h}$. Only in some weeks was electricity use higher because of some production. This suggests that the behavior change of turning off lights and machines was not linear, but was non-linear and erratic. The fluctuation was greater during the early period of the project than the later period, which means it takes time to bring a change in behavior and stabilize it. Nevertheless, VCE Braås has steadily reduced the relative idle electricity over time, from a 3-month rolling average of $28 \%$ in January 2013 to ca. 17\% in December 2016. During the same period, the actual kilowatt hour idle electricity use reduced from a 3-month rolling average of 6268 to $4246 \mathrm{kWh}$, which is a reduction of about $32 \%$. The 12month rolling average for total electricity use of the plant (not shown in the diagram), including other divisions than the fabrication division, reduced by $14 \%$. The big savings in some periods in 2015 and 2016 indicate that there is additional potential of saving idle electricity use. The big drop in idle electricity use in March 2015 was during the earth week, when there was an energy-saving competition among all the production plants of Volvo CE. The increased idle electricity use during June-December 2016 might be due to absence of control as the operational leader was on parental leave. In early 2017, the plant installed a modern equipment that increased production with lower production energy use, but still the relative idle electricity was less than the targeted $15 \%$.

\section{Interview with the Global Director}

The Global Director responsible for the energy efficiency project of Volvo CE revealed that the core environmental values of the company and the Climate Saver partnership they have with WWF have influenced him to start the energy efficiency project. The main motivation for starting

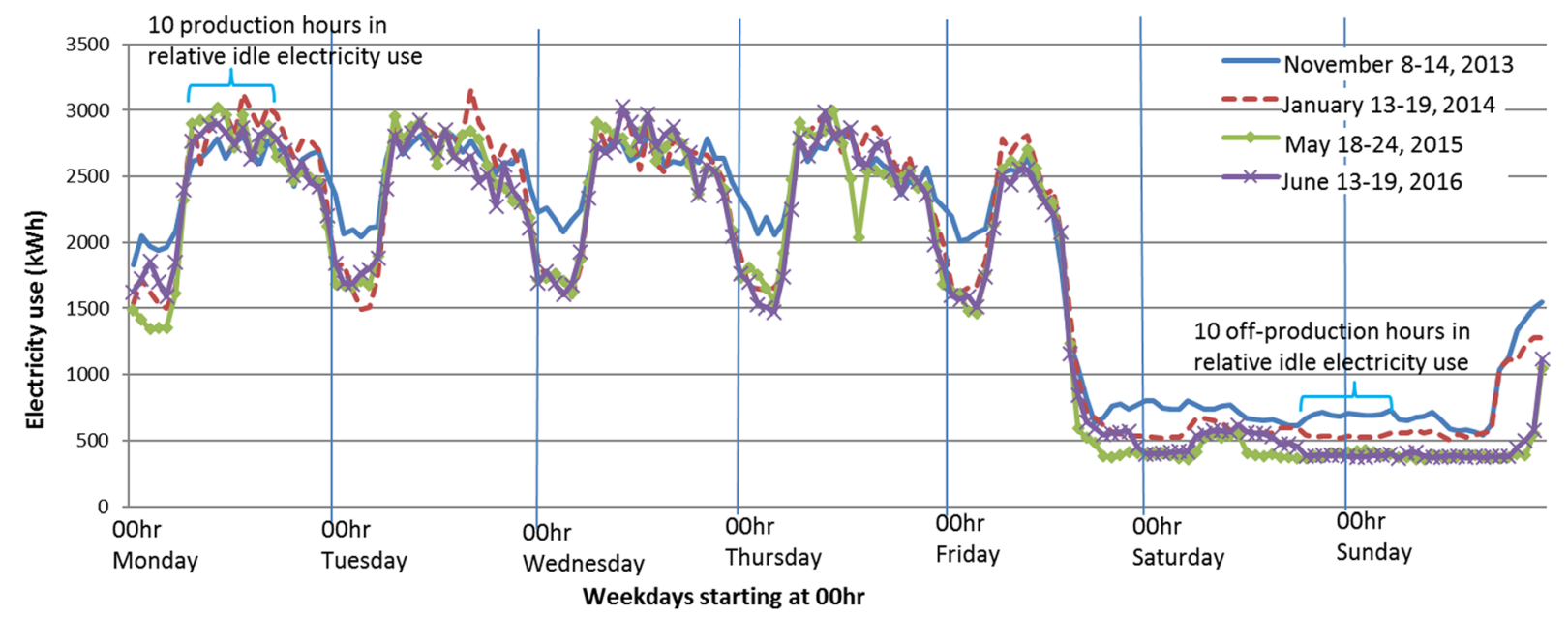

Fig. 2 Electricity consumption at VCE Braås in specific weeks in 2013, 2014, 2015, and 2016 with similar production levels 


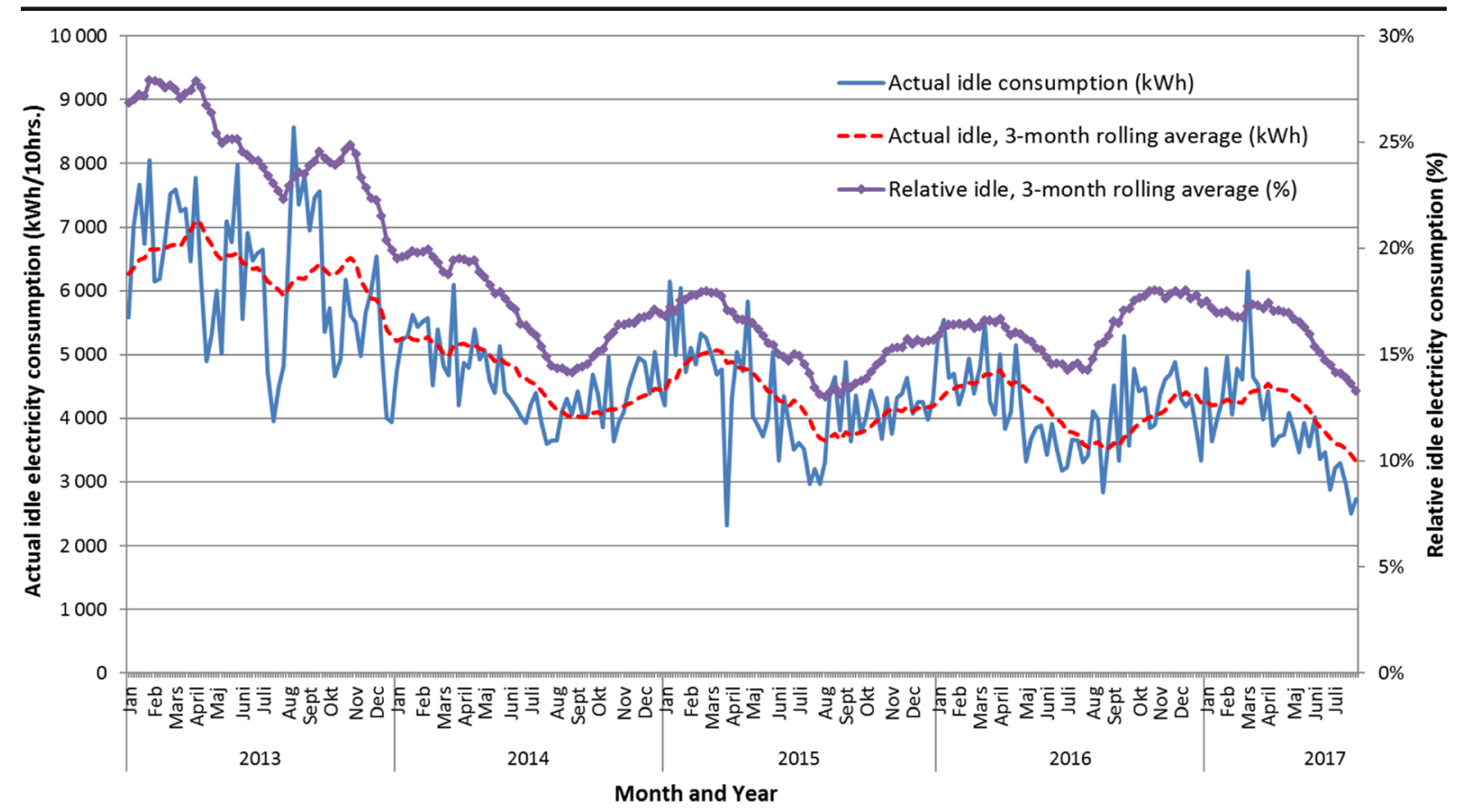

Fig. 3 Weekly actual $(\mathrm{kWh})$ idle electricity consumption of 10 off-production hours in the weekend and relative (\%) idle electricity consumption (see Eq. 1), year 2013 to mid-2017

with idle electricity use reduction was that it creates an energy efficiency culture in the company, it incurs low cost or can be self-financed, and the monetary savings can be a source of future investments in energy-efficient machines. However, it took a long time and struggle for him to get sufficient attention of the leadership on this topic. He set the $15 \%$ idle electricity use goal, but did not recommend any specific method to reach the goal. Each production plant was free to devise its own strategy and plan. However, he mentioned that nothing happens by itself, but needs to be kept on track and followed up. He has weekly meetings with the Swedish coordinator to track the progress of the Swedish sites, and the comparative achievements of all the plants are monthly communicated to the site managers, top management, and the environmental care managers, e.g., project leader at VCE Braås. He noted that it was easy for him to get good ideas as there are competent people in different plants and they have been contributing good suggestions for improvements.

Interview with the operational leader

The operational leader mentioned that he is passionate about environmental issues, which is one of the main reasons he took this job, which was a completely new area for him. He believes that everyone in the society has the responsibility to engage in sustainable activities for a greener future. For instance, he renovated his house using sustainable materials and products. Being new to the area of energy efficiency, he began by reading about energy and energy audits and realized that it is important to measure the actual energy consumption of the equipment in order to realize the target set by the company. He mentioned that employees at Braås have a culture of questioning and influencing their workplace and a good sense of team spirit. He approached the production workers group by group, starting with one that he knew would be most open and supportive to the project. He believed that he presented and explained the project as simply as possible. One of his goals was to document and show as much as possible and that each suggestion from the workers should be taken into consideration. When the first results at an early stage of the project showed this strategy working well to reduce energy, he got more confidence to continue. Besides, he got assured of his approach from the fact that other sites and companies contacted Volvo CE Braås to learn about the project.

Focus group interviews with production leaders

The production leaders seem to have good awareness of the bigger picture of environmental issue and societal 
responsibility. At home, they not only turn off the lights, $\mathrm{TV}$, etc. but also invest in sustainable technologies like solar panels. At work, they are used to turning off lights in offices and conference rooms when they notice an empty room with lights on. However, it was difficult for them to find a balance between being the one responsible for switching off the equipment at the end of the day versus transferring the responsibility to the staff by incorporating it as a staff routine. They acknowledged the important role of the operational leader and that he is "one of them."

They suggested installation of an electronic screen at the entrance of the canteen to visualize daily energy use and savings. They felt that more discussions with the floor staff would improve their awareness around this topic and encourage them to question things. They would like to get a small token and a simple as reward, which represents the company's appreciation of their efforts. They mentioned that the saved money could be spent on investing in further environmental friendly technologies to create more cost reductions or competitive advantage, such as LED lights, etc. They would also like to see that achievements of VCE Braås in environmental care are promoted and marketed more to the public and other firms. They regard this project as investment into their future, which would contribute in keeping the company competitive and a secure workplace in the long term.

Focus group interviews with group leaders

The interviewed group leaders expressed that the project was one of the numerous projects towards improvements at Volvo CE but has the highest priority right now. They were very proud to work together as a team towards the goal of energy reduction at VCE Braås and serve as a role model for other locations. However, they were not interested in a competition among teams within VCE Braås or with other sites as the situation is different, e.g., they use different equipment. They mentioned that it was important that they were asked for their opinion and were involved in the project from the beginning. Many group leaders mentioned that they had a positive attitude towards this project as the operational leader was "one of them." However, others thought that it would not make any difference to them if the person responsible would be someone else as they are used to being told instead of being asked. The interviewees mentioned that it was important to have one specific contact person who is responsible to avoid confusion. They also mentioned that the "Småland thinking" (people in Småland area of Sweden, where the plant is located, are known to try new things and are frugal) helps them to engage in the project.

The group leaders said that turning off the machines is "common sense" for them and it has quickly become a daily routine. The action of switching off is simple and an easy task. It has little influence on their routines. They also immediately discovered advantages, e.g., machines that have batteries as energy source are fully loaded on a Monday mornings. Before, batteries were often out of power and needed to be re-charged at the beginning of the week.

The group leaders control and monitor at irregular intervals (often Fridays) whether all machines are switched off. They would switch off the equipment if had not been done by their group members. There was no reprimanding for negligence, as the intention was to make the workers aware of their behavior by themselves. There was a suggestion that the responsibility of turning off the equipment at the end of a shift should be rotated within the group. This will contribute in creating an atmosphere of shared responsibilities among group members as well as engaging individuals instead of giving the group leaders the role of "monitor." Besides, some group leaders wished for smaller investments, such as movement sensors or timers. The group leaders mentioned that the existing practice, where printed papers showing the progress of the energy reduction are pasted on a whiteboard, is of little interest as there was too much information on it. For example, one group leader pointed that "sometimes too many graphs and diagrams on the whiteboard can be confusing. I would only like to get feedback about quality and how things are going (for my own group)."

Most of the group leaders regarded their effort in the energy reduction project as natural and too little to "deserve" a reward. They did not think about the monetary savings as they believed that they had no influence on financial decisions of the company. They appreciated that they got positive feedback and recognition for their efforts. For them, this project was a part of making their job more secure as there was no excessive amount of jobs available in the region. Some of them would appreciate if a group event would be sponsored or money would be to put in the group's piggy bank. One group leader mentioned that people would appreciate a monetary reward. 
Figure 4 shows the typical quotes from the focus group interviews with production leaders and group leaders corresponding to the key factors (oval shape in Fig. 1) contributing to the energy efficiency behavior of the employees. The quotes are taken from the statements that were agreed to by other members of the focus group.

Interview with floor workers

The majority of floor workers seem to have a positive attitude towards the project. They mentioned that the project gave them a sense of purpose. Their contribution to the project was small, but important part of the whole.
They emphasized that during the course of the project, the task of switching off their equipment has become an easy and simple thing to do. Some groups switch off their equipment together at the end of the shift so that no one forgets to do it. There is a general feeling of responsibility for the employee's own equipment. Some of the younger employees have taken home energy-saving action such as turning off lights and timers on power sources.

However, some of the workers questioned whether the project was about saving money or acting sustainably, and whether the savings of the project would be significant enough. Some also doubted the compatibility of the project and their work assignment and the
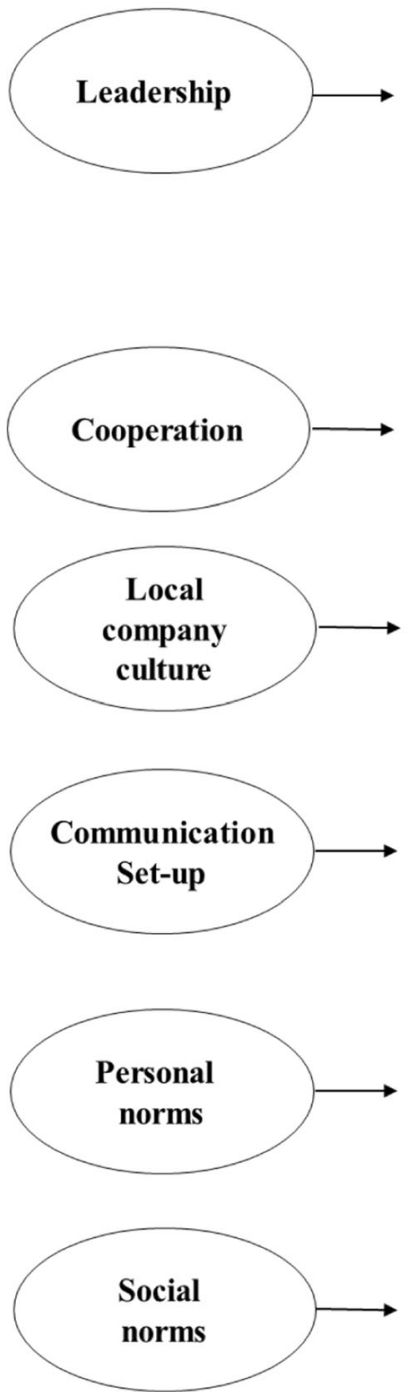

Production leader: "Our operational leader is very passionate about this project!"

Production leader: "If Frank (operational leader) wasn't there, I couldn't manage it on my own, support by someone is needed."

Production leader: "It is really important to have a driver (operational leader), who sets up goals and motivates."

Production leader: "Frank (operationalleader) said that he will fix everything. We just needed to help him by placing ourselves in the front row and say 'this is what we should do and I believe in this'; after that everything on this project kept rolling on. "'

Group leader: "We have done a precise work and tested all the machines energy consumption together. We shared our knowledge around what you should not turn off for the weekend."

Production leader: "We are a big global company, this project is not about just money. Local initiative and interest is big."

Group leader: "It is now a culture that people are more aware of energy saving and have it as a habit."

Production leader: "One of the good things Frank (operational leader) did was, visualizing the results and potential reductions."

Group leader: "I only would like to get even more feedback about quality and how things are going."

Production leader: "I give importance to minimizing energy use at home; for example, I use solar panel, have water-saving showers, only use LED lights and wood for heating"

Group leader: "Savings could go to our piggy bank as reward."

Production leader: "Local initiative and interest is big."

Production leader: "We live in Småland, we are environmentally smart and do not want to be polluters."

Fig. 4 Matching key factors affecting success of the project with typical quotes from focus group interviews 
negative side effects such as bad air, when shutting down the ventilation. Majority of the interviewed workers mentioned that there was an information meeting at the beginning of the project, but the information flow stopped afterwards. Employees who joined the plant during the course of the project did not get any or very little information about the project. They were unaware of the reasons for the project as well as results and progress. The status of the project is published in the VCE Braås magazine, but the workers had not actively searched the magazine for information. They suggested more meetings or a screen at a central place like the canteen to receive concise and updated information about the project.

Comparative assessment of the interviews

It seems that there is an agreement among the interviewed production leaders and group leaders that the fulltime employment of the operational leader was key to the success of the project. They think that it has become common to turn off machines and lights at the end of shifts and they take pride in contributing to the project. They have greater interest in environmental issues than the floor workers, some of whom wondered if the intention of the project was to save money or to act sustainably. There is also agreement that there could be better communication about the progress of the project, and that some kind of reward would further motivate the workers to engage more in the project.

\section{Discussion}

The energy efficiency achievement of VCE Braås is the outcome of a complete project setup that includes how the leadership prioritized the project and how information was shared among the stakeholders. The clear goal helped all the stakeholders to stay focused and motivated. The employment of the full-time operational leader dedicated to the project is an indication to the employees that the leadership is serious about the project. By setting up an integrative structure involving the management, production leaders, group leaders, and floor workers, the project becomes a collaborative responsibility (cooperation) instead of a top-down approach. They jointly develop and implement strategies and find solutions to problems as opposed to "dumping" the project execution on the workers.
Being part of the process right from the beginning means that the workers got an opportunity to share their knowledge and opinion, e.g., on which machines to turn off. This gave them a feeling of acknowledgement of their experience and they could feel proud that they are an important part of the whole process. Regular feedback on progress of the project and appreciation of their effort motivated the employees to sustain or improve their engagement in energy efficiency behavior. The acknowledgement and visibility was directed to a group instead of an individual. This increases motivation among co-workers to help each other to reach the goal and creates a sense of inclusiveness.

The appointment of the fulltime operational leader was an important driving force. He comes from the production floor of VCE Braås and therefore, the employees consider him as "one of them," not as a leader or outsider. The feeling of inclusiveness was strengthened as the workers saw him as their role model, who is passionate about environmental issues and deeply engaged towards the energy-saving goal. He could identify and reach out to the first production group that would be most interested in the project. These workers have a personal norm to engage in energy efficiency at home or they considered energy saving as a benefit for the company without any motivation for personal benefits. Identification of such innovators or early adopters of energy efficiency is important as they serve as role models for others to follow which steers the success of any campaign or change management project (Rogers 2003). Once a critical mass of individuals changes their personal perception and behavior, others with "old" behavior follow suit.

The personal norms seem to be derived from the social norms as indicated by the environmental profile of the company and the comments such as "Smålands thinking" denoting a culture of frugalness and thinking differently. People in general are environmentally conscious due to several initiatives in the region such as biomass-based combined heat and power production system, very efficient recycling system, biogas-based public transportation, and increased construction of wood-framed multistory buildings. The Växjö city close to the VCE Braås plant proclaims to be the Greenest city in Europe.

The communication setup is also important for the success of the project. The interviewees mentioned several times that it was very important for them to have the operational leader as a single point of contact to answer 
questions regarding the project. Also, regular updates about the progress of the project keep the employees engaged in the project. Otherwise, they may feel less responsible in reaching the common goal as no one is checking up on them and they may feel irrelevant to the project as no one takes the time to share the progress. This was evident from the lower energy saving when the operational leader was on parental leave.

In a global company like Volvo, there is the "Volvo way" culture of working. But, there is also local company culture at VCE Braås which might have influenced the employees' behavior. There is a flat hierarchy and employees are involved as much as possible in decisionmaking. There is culture of questioning and a good sense of team spirit. Moreover, the company has engaged in environmentally friendly activities, which resulted in making the plant the world's first carbon neutral manufacturing plant. Employees are not strangers to energy efficiency initiatives. All these have influenced the workers to inculcate an energy-saving culture in the company.

\section{Conclusions}

The VCE Braås energy efficiency project shows that it is indeed possible to improve energy use in manufacturing industries through a change in habitual behavior of the production workers, that to without providing any overt economic argument or incentive. From January 2013 to December 2016, the plant has reduced its idle electricity use by $32 \%$ and total electricity use by $14 \%$, and the relative idle electricity use has reached ca. $15 \%$. In fact, more than average savings in certain periods show that it could be possible to achieve more. However, it may take few years for the production workers to change their behavior as exemplified in the fluctuating idle energy use (Fig. 3). Several factors can affect the success of the change process. There must be a target for everyone to stay focused, act, and measure the progress. It is important to have dedicated leadership and continuous feedback. The project should be participative in nature, where the production workers at the bottom of the hierarchy are involved in the decision-making and are acknowledged for their effort. Especially, it seems key to identify and recruit an operational leader from the production staff, who is experienced and commands respect and trust from the colleagues. The operational leader should devout full time to the project, at least during the initial phases. At VCE Braås, the operational leader worked $100 \%$ in the project for first 2 years, but works only $50 \%$ in 2017. Then the question arises if it is cost effective to employ such a person vis-à-vis the benefits from the project.

The relative idle electricity use of VCE Braås has reduced by an average 10 percentage points, which the management estimates to be equivalent to about $€$ $86,000 /$ year (assuming $€ 1=9$ SEK). The savings could be higher if electricity prices increase in future. The initial investments on the full-time operational leader were about $€ 50,000 /$ year and now $€ 25,000$ /year now. Hence, it seems there are net monetary savings from the project, which the company considers as a source of investment for energy-efficient machines in future. There might be side benefits as well, e.g., the employees might have gained self-empowerment and a sense of meaning through the project. They seem to have better discussions with each other, which may lead to a more positive work environment, more efficient machine operations, and more skilled employees. However, these issues are not investigated in this paper and are potential topics for future research. Nevertheless, the approach to behavioral change at VCE Braås seems to be successful from the experience gained so far, but its effectiveness in the long run can be determined when there would be no operational leader to oversee the project. Moreover, the approach needs to be tested in other companies with different settings.

\section{Compliance with ethical standards}

Conflict of interest The authors declare that they have no conflict of interest.

Open Access This article is distributed under the terms of the Creative Commons Attribution 4.0 International License (http:// creativecommons.org/licenses/by/4.0/), which permits unrestricted use, distribution, and reproduction in any medium, provided you give appropriate credit to the original author(s) and the source, provide a link to the Creative Commons license, and indicate if changes were made.

\section{References}

Abdelaziz, E. A., Saidur, R., \& Mekhilef, S. (2011). A review on energy saving strategies in industrial sector. Renewable and Sustainable Energy Reviews, 15, 150-168. 
Ajzen, I. (1991). The theory of planned behavior. Organizational Behavior and Human Decision Processes, 50(2), 179-211.

Backlund, S., Broberg, S., Ottosson, M., \& Thollander, P. (2012a). Energy efficiency potentials and energy management practices in Swedish firms. In: ECEEE 2012 Industry Summer Study.

Backlund, S., Thollander, P., Palm, J., \& Ottosson, M. (2012b). Extending the energy efficiency gap. Energy Policy, 51, 392-396.

Bamberg, S., \& Möser, G. (2007). Twenty years after Hines, Hungerford, and Tomera: a new meta-analysis of psychosocial determinants of pro-environmental behaviour. Journal of Environmental Psychology, 27(1), 14-25.

Bernstein, L., Roy, J., Delhotal, K. C., Harnisch, J., Matsuhashi, R., Price, L., Tanaka, K., Worrell, E., Yamba, F., \& Fengqi, Z. (2007). Industry. In B. Metz, O. R. Davidson, P. R. Bosch, R. Dave, \& L. A. Meyer (Eds.), Climate Change 2007: Mitigation. Contribution of Working Group III to the Fourth Assessment Report of the Intergovernmental Panel on Climate Change. Cambridge and New York: Cambridge University Press.

Björkman, T., Cooremans, C., Nehler, T. \& Thollander, P. (2016). Energy management: a driver to sustainable behavioural change in companies. ECEEE 2016 Industrial Study.

Bryman, A. \& Bell, E. (2011). Business research methods, Oxford: Oxford University Press.

Bunse, K., Vodicka, M., Schönsleben, P., Brülhart, M., \& Ernst, F. (2011). Integrating energy efficiency performance in production management-gap analysis between industrial needs and scientific literature. Journal of Cleaner Production, 19, 667679.

Chirez, S. (2016). Why energy management in industrial organizations needs a refresh? ECEEE 2016 Industrial Study.

Cialdini, R. B., \& Trost, M. R. (1998). Social influence: social norms, conformity, and compliance. In D. Gilbert, S. Fiske, \& G. Lindzey (Eds.), Handbook of social psychology (pp. 151-192). Boston: McGraw- Hill.

European Commission (2017a). 2030 Energy strategy, http://ec. europa.eu/energy/en/topics/energy-strategy-and-energyunion/2030-energy-strategy, Accessed 11 Aug 2017.

European Commission (2017b). Energy trends, http://ec.europa. eu/eurostat/statistics-explained/index.php/Energy_trends, Accessed 11 Aug 2017.

Evans, M. G. (1970). The effects of supervisory behavior on the path-goal relationship. Organizational Behavior and Human Performance, 5(3), 277-298.

Flammer, C. (2013). Corporate social responsibility and shareholder reaction: the environmental awareness of investors. Academy of Management Journal, 56(3), 758-781.

Foss, N., \& Lindenberg, S. (2013). Microfoundations for strategy: a goal-framing perspective on the drivers of value creation. Academy of Management Perspectives, 27(2), 85-102.

Frederiks, E. R., Stenner, K., \& Hobman, E. V. (2015). Household energy use: applying behavioural economics to understand consumer decision-making and behavior. Renewable and Sustainable Energy Reviews, 41, 1385-1394.

Håkonsson, D. D., Obel, B., Eskildsen, J. K., \& Burton, R. M. (2016). On cooperative behavior in distributed teams: the influence of organizational design, media richness, social interaction, and interaction adaptation. Frontiers in Psychology, 7, 692. https://doi.org/10.3389/fpsyg.2016.00692.
Harland, P., Staats, H., \& Wilke, H. (1999). Explaining proenvironmental behaviour by personal norms and the theory of planned behaviour. Journal of Applied Social Psychology, 29, 2505-2528.

Johansson, M. T. (2015). Improved energy efficiency within the Swedish steel industry - the importance of energy management and networking. Energy Efficiency, 8(4), 713-744.

Kandula, S. R. (2006). Performance management. New Delhi: Prentice Hall of India private limited.

Locke, E.A., \& Latham, G.P. (1990). A theory of goal setting and task performance. Englewood.

Locke, E. A., \& Latham, G. P. (2002). Building a practically useful theory of goal setting and task motivation: a 35-year odyssey. American Psychologist, 57, 705-717.

Nisiforou, O. A., Poullis, S., \& Charalambides, A. G. (2012). Behaviour, attitudes and opinion of large enterprise employees with regard to their energy usage habits and adoption of energy saving measures. Energy and Buildings, 55, 299311.

Nixon, P., Harrington, M., \& Parker, D. (2012). Leadership performance is significant to project success or failure: a critical analysis. International Journal of Productivity and Performance Management, 61(2), 204-216.

Nordlund, A. M., \& Garvill, J. (2003). Effects of values, problem awareness, and personal norm on willingness to reduce personal car use. Journal of Environmental Psychology, 23(4), 339-347.

ODYSSEE-MURE (2015). Synthesis: energy efficiency trends and policies in the EU: an analysis based on the ODYSSEE and MURE databases., http://www.odyssee-mure. eu/publications/br/energy-efficiency-trends-policies-ineurope.html, Accessed 26 Feb 2016.

Owen, P. \& Beevor, J. (2009). Learnings from the government's act on $\mathrm{CO}_{2}$. Carbon calculator for the UK domestic sector. First European conference on energy efficiency and behaviour 2009, October 18-20. Maastricht, the Netherlands.

Rogers, E. M. (2003). Diffusion of innovations. New York: Free Press.

Rohdin, P., \& Thollander, P. (2006). Barriers to and driving forces for energy efficiency in the non-energy intensive manufacturing industry in Sweden. Energy, 31(12), 1500-1508.

Schein, E. (1990). Organizational culture and leadership. San Francisco: Jossey-Bass.

Schwartz, S. H. (1973). Normative explanations of helping behavior: a critique, proposal, and empirical test. Journal of Experimental Social Psychology, 9(4), 349-364.

SEA (2016). Lagen om energikartläggning $i$ stora företag, Swedish Energy Agency. http://www.energimyndigheten. se/energieffektivisering/lag-och-ratt/energikartlaggning-istora-foretag/, Accessed 04 Feb 2016.

Shakil, A. M. (2012). Impact of organizational culture on performance management practices in Pakistan. Business Intelligence Journal, 5(1), 50-55.

Sorrell, S., Schleich, J., Scott. S., et al. (2000). Reducing barriers to energy efficiency in public and private organizations. http://www.sussex.ac.uk/Units/spru/publications/reports/ barriers/final.html, Accessed 06 Feb 2016.

Steg, L., v. d. Berg, A. E., \& d. Groot, J. I. M. (2013). Environmental psychology: an introduction. Oxford: John Wiley \& Sons. 
Stern, P. C., Dietz, T., Abel, T., Guagnano, G. A., \& Kalof, L. (1999). A value-belief-norm theory of support for social movements: the case of environmentalism. Human Ecology Review, 6(2), 81-97.

Thøgersen, J., \& Ölander, F. (2006). The dynamic interaction of personal norms and environment-friendly buying behavior: a panel study. Journal of Applied Social Psychology, 36(7), 1758-1780.

Thollander, P., \& Ottosson, M. (2008). An energy-efficient Swedish pulp and paper industry: exploring barriers to and driving forces for cost-effective energy efficiency investments. Energy Efficiency, 1(1), 21-34.

Thollander, P., \& Ottosson, M. (2010). Energy management practices in Swedish energy-intensive industries. Journal of Cleaner Production, 18(12), 1125-1133.
Thollander, P., \& Palm, J. (2013). Improving energy efficiency in industrial energy systems. London: Springer- Verlag.

Volvo Construction Equipment 2011. Quality, environmental care \& safety, http://www.volvoce.com/SiteCollection Documents/VCE/Documents\%20Global/VCE\%20 Corporate/LD\%20Brochure\%20Core\%20Values-planche. pdf, Accessed 05 Feb 2016.

van der Werf, E., \& Steg, L. (2016). The psychology of participation and interest in smart energy systems: comparing the value-belief-norm theory and the value-identity-personal norm model. Energy Research \& Social Science, 22, 107114.

Wikipedia (2017). Organizational culture. https://en.wikipedia. org/wiki/Organizational_culture\#cite_note-1, Accessed 15 Aug 2017. 